\title{
2-Tiyourasilin Tayini için Poli(Bromokrezol moru) ile Modifiye Camsı Karbon Elektroda Dayalı Elektrokimyasal DNA Sensörü Geliștirilmesi
}

\author{
Derya Koyuncu Zeybek ${ }^{1 *}$, Burcu Demir Doğanc1², M. Özge Karaşallı ${ }^{3}$ \\ Geliş / Received: 04/10/2019 \\ Revize / Revised: 19/12/2019 \\ Kabul / Accepted: 23/12/2019
}

ÖZ

$\mathrm{Bu}$ çalı̧̧mada, potansiyel bir kanser ilacı olan 2-tiyourasil (2-TU) ilacı ile balık sperminden elde edilen çift zincirli deoksiribonükleik asit (dsDNA) molekülü arasındaki etkileşim incelenmiş ve bu etkileşime dayalı olarak ilacın elektrokimyasal tayini gerçekleştirilmiştir. Bunun için, camsı karbon elektrot (GCE) yüzeyi, bromokrezol moru (BCP) monomerinin elektrokimyasal polimerizasyonu ile modifiye edilmiş ve bu elektrot (GCE/P(BCP)) yüzeyine, dsDNA elektrokimyasal olarak immobilize edilmiştir (GCE/P(BCP)/dsDNA). dsDNA ile 2-TU arasındaki etkileşim mekanizması diferansiyel puls voltametri yöntemiyle araştırılmıştır. Bu etkileşim sonrası guaninin yükseltgenme pik akımında azalma gözlenmiş ve bu azalmaya bağlı olarak 2-TU'in elektrokimyasal tayini indirekt yöntemle gerçekleştirilmiştir. 2-TU için doğrusal çalışma aralı̆̆ $0,1-50 \mathrm{mg} \mathrm{L}^{-1}$ ve gözlenebilme sınırı $0,033 \mathrm{mg} \mathrm{L}^{-1}$ olarak bulunmuştur. 2-TU-dsDNA etkileşim mekanizması UV-Görünür bölge moleküler absorpsiyon spektroskopi yöntemiyle de incelenmiştir. Hazırlanan DNA biyosensörüne bozucu etki yapabilecek türlerin etkisi araştırılmış ve ayrıca 2-TU ilacının idrar numunesinde tayini gerçekleştirilmiştir. Deneysel çalışmalardan elde edilen sonuçlara göre, 2-TU ve dsDNA arasındaki başlıca etkileşim modunun interkalasyon olduğu belirlenmiştir.

Anahtar Kelimeler: 2-Tiyourasil, DNA Sensörü, Poli(Bromokrezol Moru), DNA-İlaç Etkileşimi

\footnotetext{
1*Sorumlu yazar iletişim: derya.kzeybek@dpu.edu.tr (http://orcid.org/0000-0003-4214-1744) Biyokimya Bölümü, Kütahya Dumlupınar Üniversitesi, Fen Edebiyat Fakültesi, 43100, Kütahya, Türkiye 2iletişim: demir.brcu@gmail.com (https://orcid.org/0000-0002-7567-1875) Biyokimya Bölümü, Kütahya Dumlupınar Üniversitesi, Fen Edebiyat Fakültesi, 43100, Kütahya, Türkiye 3İletişim: ozgekarasalli43@gmail.com (https://orcid.org/0000-0001-6614-7660) Biyokimya Bölümü, Kütahya Dumlupınar Üniversitesi, Fen Edebiyat Fakültesi, 43100, Kütahya, Türkiye.
} 


\title{
Development of Electrochemical DNA Sensor Based on Poly (Bromocresol purple) Modified Glassy Carbon Electrode for the Determination of 2-Thiouracil
}

\begin{abstract}
In this study, the interaction between 2-thiouracil (2-TU), a potential cancer drug, and double chain deoxyribonucleic acid (dsDNA) molecule obtained from fish sperm was investigated and electrochemical determination of the drug was performed. For this, the glassy carbon electrode (GCE) surface was modified by electrochemical polymerization of the bromocresol purple (BCP) monomer and dsDNA was electrochemically immobilized (GCE/P(BCP)/dsDNA) onto the surface of this electrode $(\mathrm{GCE} / \mathrm{P}(\mathrm{BCP})$ ). The interaction mechanism between dsDNA and 2-TU was investigated by differential pulse voltammetry method. After this interaction, a decrease in the oxidation peak current of guanine was observed and electrochemical determination of 2-TU was performed by indirect method due to this decrease. The linear operating range for 2-TU was 0.1-50 $\mathrm{mg} \mathrm{L}^{-1}$ and the detection limit was $0.033 \mathrm{mg} \mathrm{L}^{-1}$. The interaction mechanism of 2-TU - dsDNA was also investigated by UV-Visible molecular absorption spectroscopy. The effect of the species that may cause disruptive effect on the DNA biosensor was investigated and 2-TU drug was determined in the urine sample. According to the results obtained from experimental studies, the main mode of interaction between 2-TU and dsDNA is intercalation.
\end{abstract}




\section{GIRIS}

Urasillerin tiyo türevleri, etkili neoplastijen, tümorojen, karsinojen ve teratojen ajanlar olarak bilinirler. Bunlardan 2-Tiyourasil (4-Hidroksi-2-merkaptopirimidin, 2-TU) biyolojik ve farmasotik aktiviteleri nedeniyle önemlidirler. 2-TU, t-RNA yapısında tanımlanmıştır ve antiviral ve antikanser aktivite gösterir [1; 2]. Bunun yanında yüksek antitiroid aktivitesi nedeniyle hipertiroidizm tedavisinde kullanılır. Ayrıca melanom için spesifik bir tümör belirtecidir [3-5]. Bu nedenle, 2-TU’yu belirlemek için hızlı ve duyarlı bir yöntemin geliştirilmesi farmakokinetik ve klinik çalışmalar için oldukça önemlidir. Diğer urasil türevleri gibi 2-TU'nun tayini için de spektrofotometrik, kemilüminesans, kütle spektrometri, yüzeyde güçlendirilmiş Raman spektroskopisi ve elektrokimyasal analiz gibi yöntemler kullanılmaktadır [5-11]. Elektrokimyasal yöntemler, farklı potansiyellerde voltametrik cevap gösteren analit türlerinin araştırılmasında kullanılan yararlı yöntemlerdir. Elektrokimyasal biyosensörler üç elementten oluşur: $i$ ) biyolojik bileşen; ii) elektrokimyasal transduser; ve iii) sinyal işlemcisi. DNA molekülünün biyolojik bileşen olarak kullanıldığı elektrokimyasal DNA biyosensörleri, özellikle, DNA ve ilaç/kemoterapötik ajanlar arasındaki etkileşim mekanizmalarının çalışılması için faydalı cihazlardır. Son zamanlarda, elektrokimyasal DNA biyosensörleri ile ilgili araştırmalar hızla artmıştır [12]. Çünkü bu biyosensörler, biyolojik etkileşim olayları için küçültülebilme, yüksek hassasiyet, düşük maliyet ve kısa analiz süresi gibi avantajlara sahiptir [12;13].

Deoksiribonükleik asidin (DNA) elektrokimyasal incelenmesi biyolojik mekanizmaların çoğunun açıklanması için çok önemlidir [12]. DNA, ilaçların pek çoğu için farmakolojik bir hedeftir. İlaçların DNA ile etkileşim mekanizmasının anlaşılması, daha etkili ilaçların tasarlanması ve ilaçların plazma derişimlerinin belirlenmesinde önemli bir rol oynar [14]. Elektrokimyasal DNA biyosensörleri, nükleik asit molekülleri ve potansiyel ilaçlar, özellikle de antikanser, antibiyotik ve antiviral ilaçlar arasındaki etkileşimin çalışılması için etkili bir şekilde kullanılmaktadır. Bu etkileşimler, analiz edilen maddelerin karsinojen, toksikolojik veya farmakolojik aktiviteleri ile yakın bir ilişkiye sahiptir [12]. İlaçlar, DNA ile pek çok farklı yolla etkileşim içine girebilir: elektrostatik etkileşim, interkalasyon, büyük ve küçük oluğa bağlanma [15; 16]. DNA molekülünün elektroaktif özelliği yapısında bulunan pürin (Adenin ve Guanin) ve pirimidin (Timin ve Sitozin) bazlarından kaynaklanır. Ancak DNA-ilaç mekanizmasının araştırıldığı elektrokimyasal çalışmalarda, yaygın olarak guanin ve adenin yükseltgenme sinyallerinden yararlanılır [17]. Guanin ve adenin yükseltgenme sinyallerinin belirgin bir şekilde gözlenmesini sağlayan puls voltametrik teknikler, ekstraksiyon veya ön-işlem gereksinimi olmadan analiz imkânı sağlaması, kısa analiz süresine ve yüksek duyarlığa sahip olması gibi üstünlükleri nedeniyle ilaçDNA etkileşimi çalışmalarında oldukça sık kullanılmaktadır [18-20].

$\mathrm{Bu}$ çalışmada, antitiroid ilaç olarak kullanılan ve antikanser ilaç potansiyeli bulunan, 2-TU ilacının, dsDNA molekülü ile etkileşim mekanizması diferansiyel puls voltametri yöntemi ile araştırılmıştır. İlk olarak camsı karbon elektrot (GCE) yüzeyinde bromokrezol moru (BCP) monomerinin elektrokimyasal olarak polimerizasyonu gerçekleştirilmiştir GCE/P(BCP). Polimer modifiye elektrot yüzeyine elektrokimyasal olarak dsDNA immobilizasyonu gerçekleştirilmiştir (GCE/P(BCP)/dsDNA). Bu elektrot ile 2-TU ilacı etkileştirilmiş ve etkileşim mekanizması incelenmiştir. Hazırlanan bu DNA biyosensörü kullanılarak, idrar numunesine uygun miktarda eklenen 2-TU ilacının tayini gerçekleştirilmiştir. Ayrıca, UV-Görünür bölge moleküler absorpsiyon spektroskopi tekniği kullanılarak da etkileşim modu araştırılmıştır.

\section{MATERYAL VE YÖNTEM}

\section{A. Kimyasallar ve Kullanılan Çözeltiler}

Balık spermi dsDNA'sı Serva Company'den, bromokrezol moru (BCP, $\mathrm{C}_{21} \mathrm{H}_{16} \mathrm{Br}_{2} \mathrm{O}_{5} \mathrm{~S}$, IUPAC ismi: 4,4'-(1,1-Dioksido-3H-2,1-benzoksatiyol-3,3-diil)bis(2-bromo-6-metilfenol) monomeri, 2-Tiyourasil (2-TU, $\left.\mathrm{C}_{4} \mathrm{H}_{4} \mathrm{~N}_{2} \mathrm{OS}\right)$, dimetil sülfoksit $\left(\mathrm{C}_{2} \mathrm{H}_{6} \mathrm{OS}\right)$, sodyum asetat $\left(\mathrm{CH}_{3} \mathrm{COONa}\right)$, asetik asit $\left(\mathrm{CH}_{3} \mathrm{COOH}\right)$, sülfürik asit $\left(\mathrm{H}_{2} \mathrm{SO}_{4}\right)$, dopamin hidroklorür $\left(\mathrm{C}_{8} \mathrm{H}_{11} \mathrm{NO}_{2} . \mathrm{HCl}\right)$ Sigma-Aldrich'ten, sodyum klorür $(\mathrm{NaCl})$, askorbik asit $\left(\mathrm{C}_{6} \mathrm{H}_{8} \mathrm{O}_{6}\right)$, ürik asit $\left(\mathrm{C}_{5} \mathrm{H}_{4} \mathrm{~N}_{4} \mathrm{O}_{3}\right)$, üre $\left(\mathrm{CH}_{4} \mathrm{~N}_{2} \mathrm{O}\right)$, kreatin $\left(\mathrm{C}_{4} \mathrm{H}_{9} \mathrm{~N}_{3} \mathrm{O}_{2}\right)$, potasyum klorür $(\mathrm{KCl})$, sodyum hidroksit $(\mathrm{NaCl})$, lityum karbonat $\left(\mathrm{Li}_{2} \mathrm{CO}_{3}\right)$, magnezyum klorür $\left(\mathrm{MgCl}_{2}\right)$, kalsiyum klorür $\left(\mathrm{CaCl}_{2}\right)$ Merck'ten, di-sodyum monohidrojenfosfat dihidrat $\left(\mathrm{Na}_{2} \mathrm{HPO}_{4} \cdot 2 \mathrm{H}_{2} \mathrm{O}\right)$, sodyum dihidrojenfosfat dihidrat $\left(\mathrm{NaH}_{2} \mathrm{PO}_{4} .2 \mathrm{H}_{2} \mathrm{O}\right)$, etanol $\left(\mathrm{C} 2 \mathrm{H}_{6} \mathrm{O}\right)$ Riedel de Haën'dan temin edilmiştir. 
2-TU çözeltisi, derişimi, $100 \mathrm{mg} \mathrm{L}^{-1}$ olacak şekilde, dimetil sülfoksit-saf su karışımda hazırlandı. Derişimi $100 \mathrm{mg} \mathrm{mL}{ }^{-1}$ olan dsDNA stok çözeltisi ultra saf suyla hazırlandı ve $-20^{\circ} \mathrm{C}^{\prime}$ de saklandı. Diğer derişimdeki dsDNA çözeltileri, $20 \mathrm{mmol} \mathrm{L}^{-1} \mathrm{NaCl}$ içeren $0,5 \mathrm{~mol} \mathrm{~L}^{-1}$ asetat tampon çözeltisi (ABS, $\left.\mathrm{pH} 4,8\right)$ ile stok çözelti seyreltilerek hazırlandı. Diğer tüm çözeltileri hazırlamak için analitik saflıkta kimyasallar kullanıldı.

\section{B. Cihazlar}

Elektrokimyasal çalışmalar, bilgisayar bağlantılı Autolab-PGSTAT 204 (Eco Chemie, The Netherlands) potansiyostat/galvanostat cihazı ve ona bağlı BAS marka 3 elektrotlu elektrokimyasal hücre standı kullanılarak yapıldı. Üç elektrotlu sistem, çalışma elektrodu olarak camsı karbon elektrot (BGCE, BAS MF-2012) veya modifiye GCE, karşıt elektrot olarak platin tel (BAS MW-1032) ve referans elektrot olarak $\mathrm{Ag} / \mathrm{AgCl}\left(3 \mathrm{~mol} \mathrm{~L}{ }^{-1}\right.$ $\mathrm{NaCl}$, BAS MF-2052) elektrottan oluşmaktadır. Deneysel çalışmalar dönüşümlü voltametri (CV) kronoamperometri (CA), ve diferansiyel puls voltametri (DPV) teknikleriyle gerçekleştirildi. DPV parametreleri: potansiyel basamağı: $0,003 \mathrm{~V}$; puls genliği: $0,05 \mathrm{~V}$; puls zamanı: $0,02 \mathrm{~s}$; zaman aralığı: $0,2 \mathrm{~s}$ ve tarama hızı: $0,015 \mathrm{~V} \mathrm{~s}^{-1}$. Elde edilen veriler NOVA 1.10.4 yazılımı ile değerlendirildi. UV-Görünür bölge moleküler absorpsiyon spektrumları Shimadzu UV-2550 spektrofotometre cihazında $1 \mathrm{~cm}$ 'lik kuvars küvetler içerisinde ölçümler yapılarak kaydedildi. Numunelerin absorpsiyon spektrumları 225-400 nm dalga boyu aralığında kaydedildi. pH ölçümleri Mettler Toledo FE20 pH metre (Mettler Toledo, China) kullanılarak gerçekleştirildi. Tüm çözeltiler Millipore Synergy (Merck, France) cihazından elde edilen ultra-saf suyla $(18,2 \mathrm{M} \Omega \mathrm{cm})$ hazırlandi.

\section{DNA Biyosensörünün Hazırlanması}

Camsı karbon elektrot (GCE) yüzeyi, 0,05 $\mu \mathrm{m}$ alümina süspansiyonu ile temizleme pedi kullanılarak temizlendi. Elektrotlar, sırasıyla, saf su ve etanol içerisinde ultrasonikatörde tutuldu ve havada kurutuldu. Daha sonra çalışma elektrodu, $0,50 \mathrm{~mol} \mathrm{~L}^{-1}$ derişimindeki $\mathrm{H}_{2} \mathrm{SO}_{4}$ çözeltisinde dönüşümlü voltamogramlar $(\mathrm{CV})$ alınarak elektrokimyasal olarak temizlendi (Potansiyel aralı̆̆ı: $(-0,5)-(+1,5) \mathrm{V}$, tarama hızı: $100 \mathrm{mV} \mathrm{s}^{-1}$, Döngü Sayısı: 20).

Temizlenmiş GCE yüzeyine, $5 \times 10^{-4} \mathrm{~mol} \mathrm{~L}^{-1} \mathrm{BCP}$ monomeri içeren $0,10 \mathrm{~mol} \mathrm{~L}^{-1} \mathrm{PBS}(\mathrm{pH} 6,0)$ içerisinde, CV yöntemiyle, poli(bromokrezol moru) (P(BCP)), elektropolimerizasyon yoluyla kaplandı. Elektropolimerizasyon, $(-0,4)-(+1,8) \mathrm{V}$ potansiyel aralığında, $100 \mathrm{mV} \mathrm{s}$ tarama hızında, 50 döngü ile gerçekleştirildi [21]. Hazırlanan bu elektrot GCE/P(BCP) olarak gösterildi ve daha sonra oda sicaklığında kurutulmaya birakıldı.

dsDNA'nın, poli(bromokrezol moru) modifiye çalışma elektroduna immobilizasyonu, $30 \mathrm{mg} \mathrm{L}^{-1}$ dsDNA ve 20 mmol L ${ }^{-1} \mathrm{NaCl}$ içeren $0,5 \mathrm{~mol} \mathrm{~L}^{-1} \mathrm{ABS}$ 'de (pH 4,8) 240 saniye süreyle Ag/AgCl'e karş1 +0,5 V potansiyel uygulanarak kronoamperometri $(\mathrm{CA})$ tekniği ile gerçekleştirildi. $\mathrm{Bu}$ işlem sonrası $\mathrm{P}(\mathrm{BCP})$ modifiye GCE’ye bağlanmamış dsDNA moleküllerini uzaklaştırmak için çalışma elektrodu birkaç kez ABS ile yıkandı ve daha sonra kurutuldu. Bu elektrot GCE/P(BCP)/dsDNA olarak adlandırıldı.

\section{2-TU ile dsDNA'nın Etkileşimi}

2-TU ve dsDNA arasındaki etkileşim, guanin yükseltgenme sinyalindeki değişime bağlı olarak çalışıldı. Bunun için optimize koşullarda (optimum dsDNA miktarı, optimum dsDNA immobilizasyon süresi, ilaçdsDNA etkileşim süresi) $\mathrm{GC} / \mathrm{P}(\mathrm{BCP}) / \mathrm{dsDNA}$ elektrot, $0,1-50 \mathrm{mg} \mathrm{L}^{-1}$ derişimlerdeki çeşitli 2-TU çözeltilerinde bekletildi. Etkileşim sonrasında $20 \mathrm{mmol} \mathrm{L}{ }^{-1} \mathrm{NaCl}$ içeren $0,5 \mathrm{~mol} \mathrm{~L}^{-1} \mathrm{ABS}$ çözeltisi içerinde, $(+0,5 \mathrm{~V})-(+1,3$ V) (Ag/AgCl'e karşı) potansiyel aralığında diferansiyel puls voltamogramları kaydedildi ve guanin sinyalleri belirlendi. Daha sonra ilaç derişimlerine karşı guanin sinyalleri grafiğge geçirilerek kalibrasyon eğrisi elde edildi. İlaçların dsDNA ile elektrokimyasal etkileşimi sonrası çizilen kalibrasyon eğrileri üzerinden doğrusal çalışma aralığı ve gözlenebilme sınırı (LOD) hesaplandı.

\section{E. İdrar Numunesinde 2-TU analizi}


Sağlıklı bir bireyden alınan $10 \mathrm{~mL}$ idrar numunesi 30 dakika $2000 \mathrm{rpm}$ de santrifüjlendi ve süpernatant sıvı alınarak Agilent marka 0,45 $\mu \mathrm{m}$ 'lik filtre ile süzüldü. Süzülen kısımda 1,0 mL'lik örnekler alınarak buzdolabında $4{ }^{\circ} \mathrm{C}$ 'de depolandı. İdrar örneğine belli derişimde olacak şekilde 2-TU ilave edilerek \% geri kazanım ve \% bağıl standart hata değerleri hesaplandı.

\section{BULGULAR}

2-Tiyourasilin elektrokimyasal tayinini gerçekleştirmek ve dsDNA ile etkileşim modunun araştırılması için ilk olarak hazırlanan P(BCP) modifiye GC elektrotlara dsDNA immobilize edildi. Bu aşamada immobilize edilen dsDNA miktarı ve immobilizasyon süresi optimize edildi [19]. Buna göre, optimum dsDNA miktarı ve optimum immobilizasyon süresi sırasıyla, $30 \mathrm{mg} \mathrm{L}^{-1}$ ve $240 \mathrm{~s}$ olarak alındı. 2-TU ile ilgili yapılan diğer deneysel çalışmalar aşağıda sunuldu.

\section{A. 2-TU ile dsDNA Arasındaki Etkileşim Sürenin Belirlenmesi}

dsDNA immobilize edilmiş modifiye elektrot (GCE/P(BCP)/dsDNA) ile 2-TU ilacı arasındaki etkileşim süresinin belirlenmesi için hazırlanan elektrot, 30-240 saniye sürelerinde 2-TU çözeltisi içinde bekletildi. Etkileşim sonrası 20 mmol L ${ }^{-1} \mathrm{NaCl}$ içeren $0,5 \mathrm{~mol} \mathrm{~L}^{-1} \mathrm{ABS}(\mathrm{pH} 4,8)$ ortamında (+0,5 V)-(+1,3 V) (Ag/AgCl'e karşı) potansiyel aralığında DPV'ler alınarak, guanin yükseltgenme pik akımları belirlendi ve süreye karşı grafiğe geçirildi (Şekil 1). Şekil incelendiğinde, etkileşim süresi arttıkça guanin sinyallerinin azaldığı görüldü. $\mathrm{Bu}$ azalma oranının neredeyse sabit kaldığ süre olan 120 saniye 2-TU için optimum etkileşim süresi olarak seçildi.

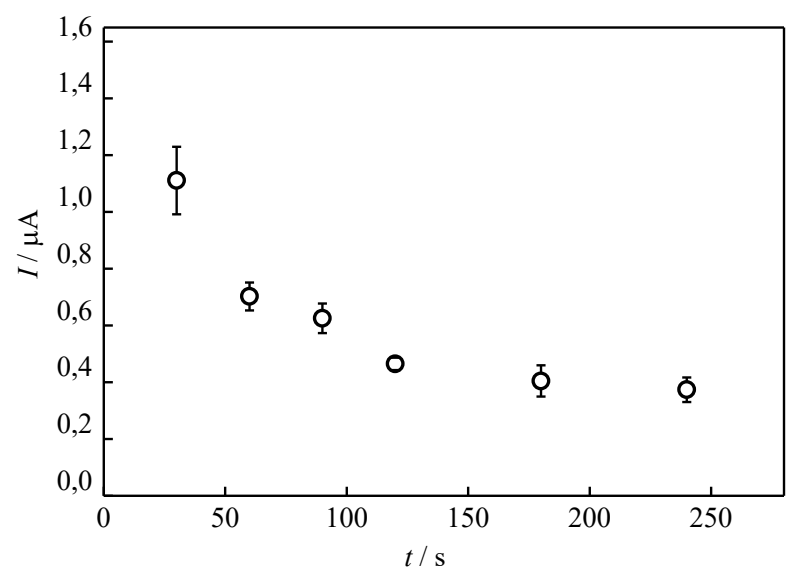

Şekil 1. GCE/P(BCP)/dsDNA elektrodu ile 2-TU ilacının farklı etkileşim süreleri için guanin yükseltgenme pik akım cevapları (Hata çubukları 3 ölçüm için elde edilmiştir)

\section{B. 2-TU ile dsDNA Etkileşimi ve Analitik Parametreler}

Optimize edilen koşullar kullanılarak, 2-TU ilacının tasarlanan DNA biyosensörü ile tayin edilip edilemeyeceği ve ilaç-dsDNA arasındaki etkileşim tipi araştırıldı. GCE/P(BCP)/dsDNA elektrot, farklı derişimlerde (0,1-50 $\left.\mathrm{mg} \mathrm{L}^{-1}\right)$ 2-TU içeren çözeltilerde $120 \mathrm{~s}$ bekletildi. Etkileşim sonrası DPV'ler kaydedildi ve ilaç derişiminin artışıyla, guanin yükseltgenme sinyallerinin azaldığı görüldü (Şekil 2). Grafik incelendiğinde, guanin yükseltgenme akımlarının etkileşim sonrasında azaldığı ve genel olarak artan 2-TU derişimi ile pik potansiyellerinin daha pozitif değerlere kaydığı görüldü. 2-TU ile dsDNA arasındaki etkileşimin interkalasyon yoluyla olduğu söylenebilir [22]. 


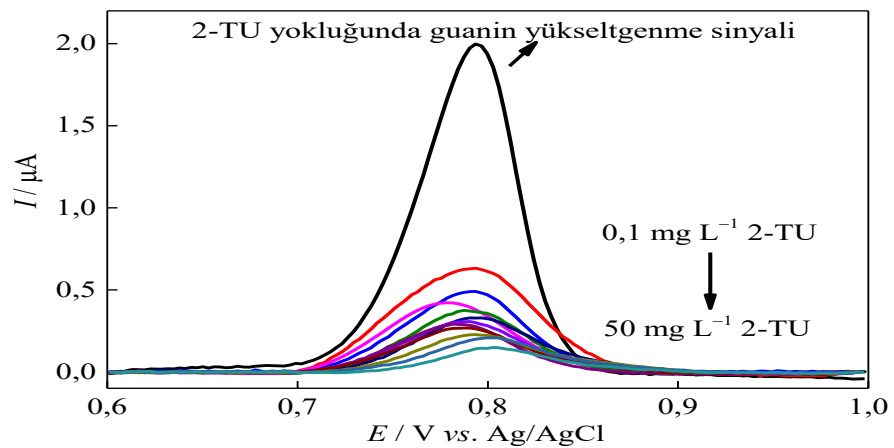

Şekil 2. 2-TU ile etkileșim öncesi ve farklı derişimlerde $\left(0,1 \mathrm{mg} \mathrm{L}^{-1}-50 \mathrm{mg} \mathrm{L}^{-1}\right)$ 2-TU ile etkileşim sonrası elde edilen guanin yükseltgenme pik akımları

Şekil 2'de görülen 2-TU derişiminin artışı ile guanin sinyalindeki azalma, 2-TU tayini için bir gösterge olarak kullanılması düşünüldü ve guanin yükseltgenme pik akımları, ilaç derişimine karşı grafiğe geçirildi (Şekil 3) ve iki doğrusal çalışma aralığı gözlendi. Elde edilen analitik parametreler Tablo 1'de verildi.

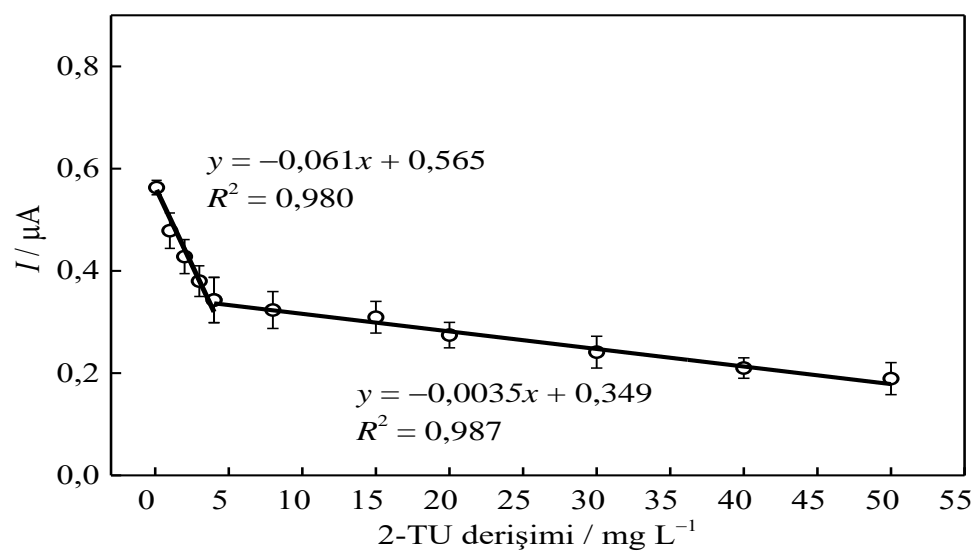

Şekil 3. 2-TU'nun kalibrasyon eğrisi (GCE/P(BCP)/dsDNA elektrot) (Hata çubukları 3 ölçüm için elde edilmiştir)

Tablo 1. 2-TU için elde edilen analitik parametreler

\begin{tabular}{lcc}
\hline \multicolumn{1}{c}{ Parametre } & \multicolumn{2}{c}{ Sonuç } \\
\cline { 2 - 3 } & 1. doğrusal aralık & 2. doğrusal aralık \\
\hline Doğrusal aralık $\left(\mathrm{mg} \mathrm{L}^{-1}\right)$ & $0,1-4,0$ & $4,0-50,0$ \\
Gözlenebilme sınırı ve alt tayin sınırı $\left(\mathrm{mg} \mathrm{L}^{-1}\right)$ & 0,033 ve 0,100 & - \\
Eğim $\left(\mu \mathrm{A} \mathrm{L} \mathrm{mg}^{-1}\right)$ & 0,0610 & 0,0035 \\
Determinasyon katsayısı $\left(R^{2}\right)$ & 0,980 & 0,987 \\
Kesim noktası $(\mu \mathrm{A})$ & 0,565 & 0,349 \\
Eğimin standart sapması $\left(\mu \mathrm{A} \mathrm{L} \mathrm{mg}{ }^{-1}\right)$ & $5,05 \times 10^{-3}$ & $1,66 \times 10^{-4}$ \\
Kesim noktasının standart sapması $(\mu \mathrm{A})$ & $8,30 \times 10^{-3}$ & $5,00 \times 10^{-3}$ \\
\hline
\end{tabular}


GCE/P(BCP)/dsDNA elektrot ile elde edilen ve literatürde bildirilen sonuçlar Tablo 2'de karşılaştırıldı. $\mathrm{Bu}$ çalışmada, dsDNA esas alınarak dolaylı bir tayin işlemi yapılmış olup literatürde 2-TU'in elektrokimyasal yükseltgenmesini esas alarak doğrudan tayin işlemi gerçekleştirilmiştir. Bu çalışmada geliştirilen DNA sensörü, 2-TU tayini için düşük gözlenebilme sınırına ve geniş doğrusal aralığa sahiptir ve literatürdeki çalışmalarla karşılaştırılabilir bir performans sergilemiştir.

Tablo 2. 2-TU tayini için farklı elektrokimyasal sensörlerin performanslarının karşılaştırılması.

\begin{tabular}{|c|c|c|c|c|}
\hline Yöntem / Elektrot & Doğrusal aralık & LOD & LOQ & Kaynak \\
\hline $\begin{array}{l}\text { Merdiven voltametri / } \\
\text { poli(pirol) film modifiye } \\
\text { grafit kalem elektrot }\end{array}$ & $0,01-0,15 \mu \mathrm{mol} \mathrm{L}-1$ & $1,63 \mathrm{nmol} \mathrm{L}^{-1}$ & $5,05 \mathrm{nmol} \mathrm{L}^{-1}$ & [1] \\
\hline $\begin{array}{l}\text { Merdiven voltametri / } \\
\text { poli(anilin) film modifiye } \\
\text { grafit kalem elektrot }\end{array}$ & $0,01-0,13 \mu \mathrm{mol} \mathrm{L}^{-1}$ & $1,81 \mathrm{nmol} \mathrm{L}^{-1}$ & $6,30 \mathrm{nmol} \mathrm{L}-1$ & [1] \\
\hline $\begin{array}{l}\text { DPV / Kobalt ftalosiyanin } \\
\text { ile modifiye edilmiş } \\
\text { karbon pasta elektrot }\end{array}$ & $0,70-800 \mathrm{mmol} \mathrm{L}^{-1}$ & $40,0 \mu \mathrm{mol} \mathrm{L}^{-1}$ & - & [8] \\
\hline $\mathrm{DPV} / \mathrm{TiO}_{2}$ & & & & \\
\hline $\begin{array}{c}\text { nanopartikül modiye altın } \\
\text { elektrot }\end{array}$ & $0,10-5,0 \mu \mathrm{mol} \mathrm{L}^{-1}$ & $1,68 \mathrm{nmol} \mathrm{L}^{-1}$ & $5,60 \mathrm{nmol} \mathrm{L}^{-1}$ & [10] \\
\hline $\begin{array}{l}\text { Kare dalga voltametri / } \\
\text { Camsı karbon elektrot }\end{array}$ & $1,00-20 \mu \mathrm{mol} \mathrm{L}-1$ & $0,16 \mu \mathrm{mol} \mathrm{L}^{-1}$ & $0,53 \mu \mathrm{mol} \mathrm{L}^{-1}$ & [23] \\
\hline $\begin{array}{l}\mathrm{DPV} / \mathrm{NiSO}_{4} \text { modifiye } \\
\text { karbon pasta elektrot }\end{array}$ & $0,10-1,00 \mu \mathrm{mol} \mathrm{L}^{-1}$ & $2,10 \mathrm{nmol} \mathrm{L}^{-1}$ & $6,90 \mathrm{nmol} \mathrm{L}-1$ & [24] \\
\hline $\begin{array}{c}\text { Diferansiyel puls } \\
\text { adsorptif siyırma } \\
\text { voltametri / Polibenzoin } \\
\text { modifiye karbon pasta } \\
\text { elektrot }\end{array}$ & $0,20-1,20 \mu \mathrm{mol} \mathrm{L}^{-1}$ & $2,21 \mathrm{nmol} \mathrm{L}^{-1}$ & 7,38 $\mathrm{nmol} \mathrm{L}{ }^{-1}$ & [25] \\
\hline DPV / Altın elektrot & $1,00-11,0 \mu \mathrm{mol} \mathrm{L}^{-1}$ & $20,5 \mathrm{nmol} \mathrm{L}^{-1}$ & $68,2 \mathrm{nmol} \mathrm{L}^{-1}$ & [26] \\
\hline $\begin{array}{c}\mathrm{DPV} / \\
\mathrm{GCE} / \mathrm{P}(\mathrm{BCP}) / \mathrm{dsDNA}\end{array}$ & $\begin{array}{c}0,10-50,0 \mathrm{mg} \mathrm{L}^{-1} \\
\left(0,79-394 \mu \mathrm{mol} \mathrm{L}^{-1}\right)\end{array}$ & $\begin{array}{c}0,033 \mathrm{mg} \mathrm{L}^{-1} \\
(0,26 \mu \mathrm{mol} \\
\left.\mathrm{L}^{-1}\right)\end{array}$ & $\begin{array}{l}0,10 \mathrm{mg} \mathrm{L}^{-1} \\
(0,79 \mu \mathrm{mol} \\
\left.\mathrm{L}^{-1}\right)\end{array}$ & $\begin{array}{c}\mathrm{Bu} \\
\text { çalışma }\end{array}$ \\
\hline
\end{tabular}

Elde edilen veriler 1şığında ilacın bağlanma sabiti aşağıdaki eşitlik kullanılarak hesaplandı. [27].

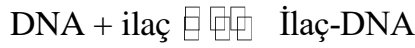

$\log \left(\frac{1}{I_{\text {ilą̧ }}}\right)=\log K+\log \left(\frac{I_{\text {ilaç-DNA }}}{I_{\mathrm{DNA}}-I_{\text {ilaç-DNA }}}\right)$ 
$K$ : bağlanma sabiti

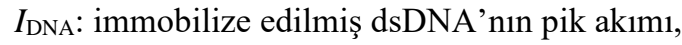

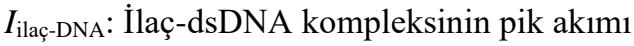

2-TU bağlanma sabiti $K=2,1 \times 10^{5} \mathrm{~L} \mathrm{~mol}^{-1}$ olarak hesaplandı.

Literatürde yer alan çalışmalar incelendiğinde, interkalasyon yolu ile DNA ile etkileşime giren ilaçlar için bağlanma sabitleri genel olarak $10^{4}-10^{5}$ olarak bulunmuştur [28; 29].

\section{Girişim Yapabilecek Türlerin Cevap Üzerine Etkisinin İncelenmesi}

2-TU tayini için geliştirilen DNA biyosensörünün, seçiciliğini araştırmak amacıyla, askorbik asit (AA), ürik asit (UA), dopamin (DA), üre, kreatin gibi moleküler türlerin ve magnezyum $\left(\mathrm{Mg}^{2+}\right)$, kalsiyum $\left(\mathrm{Ca}^{2+}\right)$, potasyum $\left(\mathrm{K}^{+}\right)$gibi iyonların guanin sinyali üzerine etkisi çalışıldı. Bunun için 2-TU derişimi $2,0 \mathrm{mg} \mathrm{L}^{-1}$ ve ilgili türlerin derişimi $0,1 \mathrm{mmol} \mathrm{L}{ }^{-1}$ olan çözeltide DPV ölçümleri gerçekleştirildi. Elektrodun guanin piki için akım değerleri ve standart sapmaları Şekil 4'te gösterildi. Bağıl hatanın $\pm \% 9$ 'un altında olduğu görüldü. Hazırlanan elektrokimyasal biyosensörün 2-TU için iyi bir seçiciliğe sahip olduğu söylenebilir.

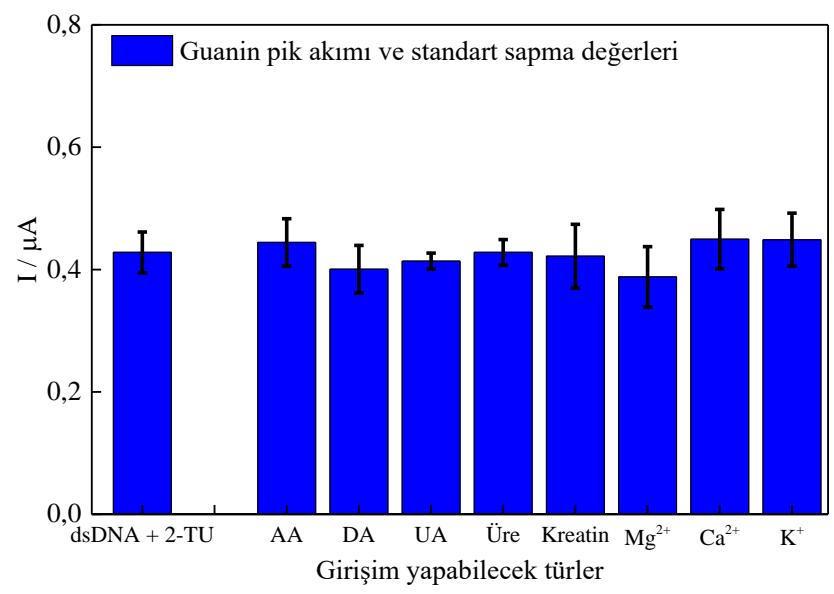

Şekil 4. 2-TU için GCE/P(BCP)/dsDNA elektrodun ilgili türler varlığında görülen DPV pik akım değerleri ve standart sapmaları

\section{D. $\mathrm{NaCl}$ Etkisinin Incelenmesi}

dsDNA ile 2-TU arasındaki etkileşimini daha iyi açıklayabilmek için, GCE/P(BCP)/dsDNA elektrotta guanin yükseltgenme sinyaline, iyonik gücün etkisi araştırıldı. Bunun için GCE/P(BCP)/dsDNA $\left(30 \mathrm{mg} \mathrm{L}^{-1}\right)$ elektrotlar, 2-TU derişimi 2,0 $\mathrm{mg} \mathrm{L}^{-1}$ olacak şekilde ilaç ile etkileşime sokuldu. Elektrodun, $\mathrm{NaCl}$ derişimi 2,5$20 \mathrm{mmol} \mathrm{L}^{-1}$ olacak şekilde hazırlanan $0,5 \mathrm{mmol} \mathrm{L}^{-1}$ ABS $(\mathrm{pH} \mathrm{4,8)}$ tampon içerisinde ayrı ayrı diferansiyel puls voltamogramları kaydedildi. Voltamogramlardan yararlanılarak $\mathrm{NaCl}$ derişimine karşı guanin pik akımları grafiğe geçirildi (Şekil 5).

2-TU için guanin yükseltgenme sinyallerinin $10 \mathrm{mmol} \mathrm{L}^{-1} \mathrm{NaCl}$ derişimine kadar arttı̆̆ daha sonra ise önemli bir değişikliğin olmadığı görüldü. $\mathrm{Bu}$ şekilde bir davranış düşük $\mathrm{NaCl}$ derişimlerinde ilgili ilaçların dsDNA'nın negatif yüklü fosfat gruplarına elektrostatik olarak bağlandığını gösterir. Ancak derişim arttıkça dsDNA, pozitif yüklü $\mathrm{Na}^{+}$iyonları ile daha fazla çevrelenir. Bunun sonucunda ilaçların dsDNA ile elektrostatik etkileşimi azalır. $\mathrm{Bu}$ sebepten yüksek $\mathrm{NaCl}$ derişimlerinde dsDNA-ilaç etkileşiminin başlıca interkalasyon yoluyla olduğu söylenebilir [27]. dsDNA negatif yüklerin iyonik koruyucu kalkan oluşturması sebebiyle iyonik kuvvet arttıkça ilaç molekülleri dsDNA çift sarmal arasına interkale olurlar. 


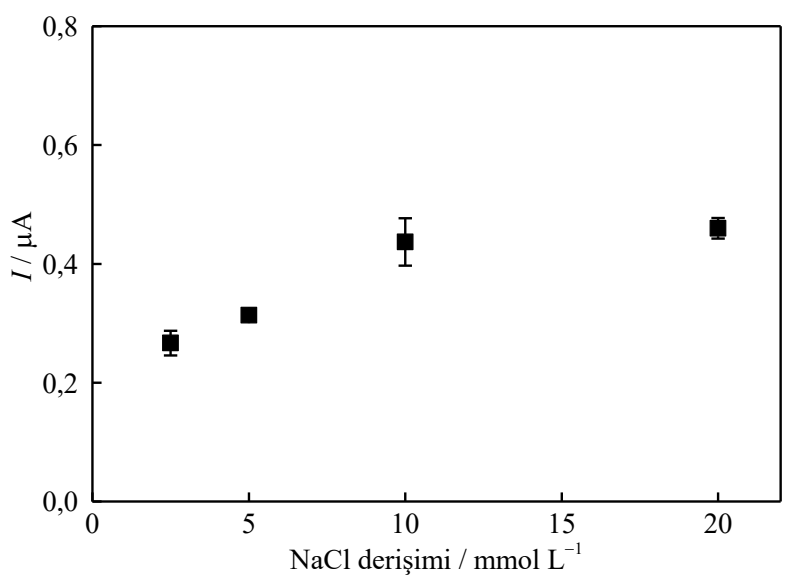

Şekil 5. dsDNA- 2-TU etkileşimi üzerine $\mathrm{NaCl}$ derişimin etkisi (Hata çubukları 3 ölçüm için elde edilmiş̧tir)

\section{E. Tekrarlanabilirlik}

dsDNA immobilize edilmiş modifiye elektrodun tekrarlanabilirliği, dsDNA ile 2-TU'nun etkileşimi sonrası guanin yükseltgenme sinyaline dayalı ölçümler yaparak incelendi. Gün içi ve günler arası \% BSS değeri srasıly $\% 2,6$ ve $\% 2,2$ olarak belirlendi.

\section{E. İdrar Örneğinde 2-Tiyourasil Tayininin Yapılmast}

Hazırlanan DNA biyosensörünün idrar örneğindeki 2-TU tayini için kullanıp kullanılmayacağ araştırıldı. Bunun için belli miktarlarda stok 2-TU çözeltisinden ön muamele edilmiş idrar örneklerine ilaveler yapıldı ve kalibrasyon grafiği kullanılarak idrar numunesi içerisindeki ilaç miktarları bulundu. $\mathrm{GCE} / \mathrm{P}(\mathrm{BCP}) / \mathrm{dsDNA}$ elektrot ile analiz sonucunda bağıl standart sapmalar ve \% geri kazanım değerleri hesaplandi (Tablo 3).

Tablo 3. İdrar numunesinde 2-TU analizi (Sonuçlar 3 ölçüm için verilmiştir).

\begin{tabular}{ll}
\hline \multicolumn{1}{c}{ İdrar Numunesi } & GCE/P(BCP)/dsDNA \\
\hline İdrara eklenen $\left(\mathrm{mg} \mathrm{L}^{-1}\right)$ & 2,00 \\
Bulunan miktar $\left(\mathrm{mg} \mathrm{L}^{-1}\right)$ & $2,21 \pm 0,12$ \\
Geri kazanım (\%) & 110,75 \\
BSS (\%) & 5,40 \\
\hline İdrara eklenen $\left(\mathrm{mg} \mathrm{L}^{-1}\right)$ & 10,00 \\
Bulunan miktar $\left(\mathrm{mg} \mathrm{L}^{-1}\right)$ & $10,75 \pm 0,64$ \\
Geri Kazanım $(\%)$ & 107,50 \\
BSS (\%) & 5,92 \\
\hline
\end{tabular}




\section{F. dsDN-2TU Etkileşiminin Spektroskopik Olarak Incelenmesi ve Etkileşim Modunun Belirlenmesi}

Bağlanma parametrelerinin saptanabilmesi için absorbans ve dalga boyundaki değişimler de kullanılabilir. Bu sebepten UV-Görünür bölge moleküler absorpsiyon spektroskopisi, dsDNA ile 2-TU ilacı arasındaki etkileşim modunun aydınlatılması için kullanıldı. Ligand olarak kullanılan küçük maddeler absorbans bandında/dalga boyunda ve absorbans değerlerinde değişiklikler oluşturur. Bu değişikleri anlamak için dsDNAilaç etkileşimi sonrası alınan spektrumda en yüksek absorbansın gözlendiği dalga boyundaki kaymalar incelenir. DNA'ya interkalasyon yoluyla bağlanan ilaçlar genellikle hipokromizme ve batokromizme (kırmızı kayma) yol açabilir. Çünkü interkalatif mod DNA'nın baz çiftleri ile aromatik kromofor arasındaki istiflenme etkileşimini içerir. DNA ve ilaç arasında elektrostatik etkileşim olduğunda ise hiperkromik etki gözlenir. Küçük moleküllerin DNA oluklarına bağlanması halinde ise önemli bir kayma gözlenmez [14].

DNA ile diğer moleküller etkileşime geçtiğinde çift sarmal dsDNA yapısındaki değişiklikler sonucu izlenen spektral özellikler hiperkromizm ve hipokromizm olarak kabul edilir. Hiperkromizm ikincil DNA yapısının kopması anlamına gelmektedir. Hipokromizm ise elektrostatik etki ile ya da küçük moleküllerin interkalasyon bağlanma modunda DNA dubleks stabilizasyonunu ifade eder [30].

Şekil 6'da serbest 2-TU (10 $\left.\mathrm{mg} \mathrm{L}^{-1}\right)$ ve serbest dsDNA $\left(30 \mathrm{mg} \mathrm{L}^{-1}\right)$ absorpsiyon spektrumları görülmektedir. Serbest 2-TU için $275 \mathrm{~nm}$ 'de maksimum absorbans gözlenirken, dsDNA için ise $260 \mathrm{~nm}$ 'de maksimum absorbans elde edildi.

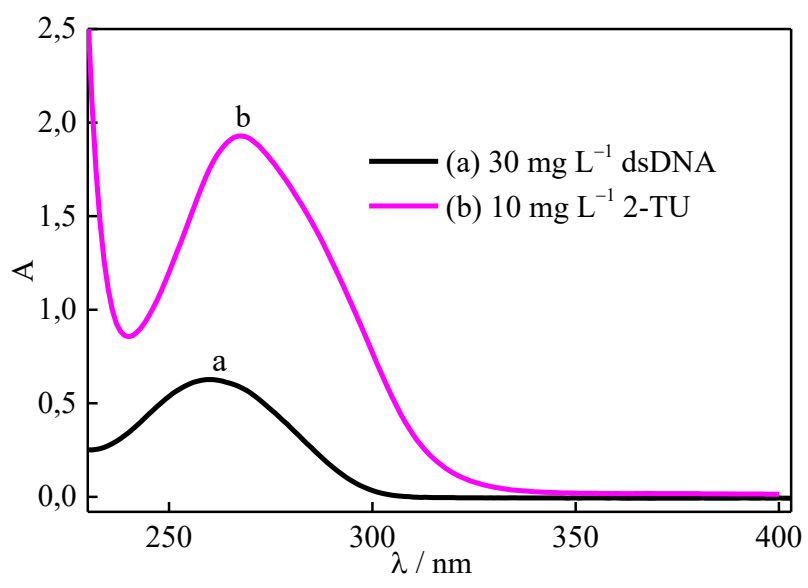

Şekil 6. Serbest 2-TU $\left(10 \mathrm{mg} \mathrm{L}^{-1}\right)$ ve serbest dsDNA'nın $\left(30 \mathrm{mg} \mathrm{L}^{-1}\right)$ UV-Görünür bölge moleküler absorpsiyon spektrumları

2-TU ile etkileşim öncesi ve sonrası elde edilen spektrumlar ise Şekil 7'de verildi. Artan derişimlerde 2TU ilave edildiğinde, yaklaşık $260 \mathrm{~nm}$ dalga boyundaki dsDNA pik absorbansının arttığı ve daha uzun dalga boylarına doğru hafif bir kayma gösterdiği belirlendi. dsDNA'nın absorpsiyon spektrumundaki değişiklik 2-TUdsDNA kompleksinin oluşumuna atfedilebilir. 


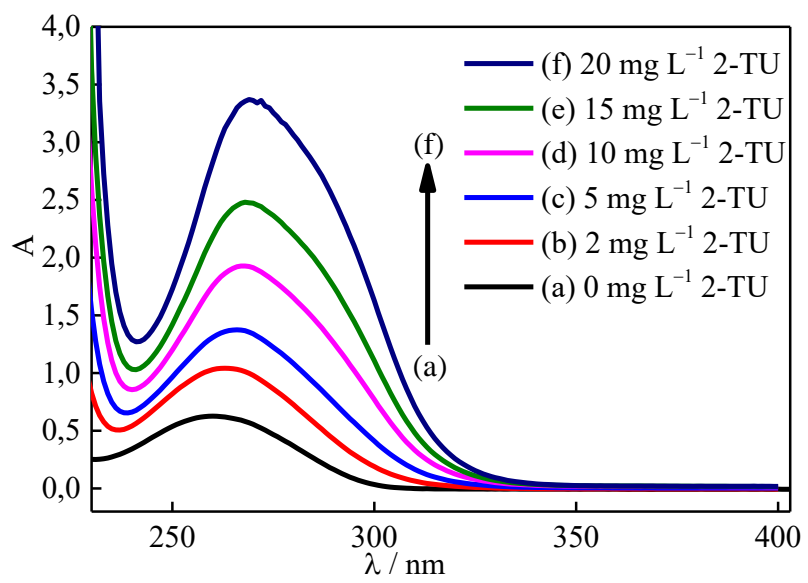

Şekil 7. dsDNA (30 $\left.\mathrm{mg} \mathrm{L}^{-1}\right)$ ve 2-TU yokluğunda ve varlığında $\left(2-20 \mathrm{mg} \mathrm{L}^{-1}\right)$ UV-Görünür bölge moleküler absorpsiyon spektrumları

UV-Görünür bölge moleküler absorpsiyon spektroskopisi ile elde edilen veriler kullanılarak aşağıdaki eşitliğe göre 2-TU ilacının bağlanma sabiti $(K)$ hesaplanabilir:

$$
\frac{\mathrm{A}_{\mathrm{o}}}{\mathrm{A}-\mathrm{A}_{\mathrm{o}}}=\frac{\varepsilon_{\mathrm{G}}}{\varepsilon_{\mathrm{H}-\mathrm{G}}}+\frac{\varepsilon_{\mathrm{G}}}{\varepsilon_{\mathrm{H}-\mathrm{G}}} \times \frac{1}{K[\text { ilaç }]}
$$

$K$ : bağlanma sabiti, A ve $\mathrm{A}_{0}$ : ilaç varlığında ve yokluğunda dsDNA'nın absorbansı, $\varepsilon_{\mathrm{G}}$ ve $\varepsilon_{\mathrm{H}-\mathrm{G}}$ : dsDNA ve ilaç-dsDNA kompleksinin absorpsiyon katsayısıdır.

1/(A- $\left.\mathrm{A}_{\mathrm{o}}\right)^{\prime} \mathrm{a}$ karş1 $1 / K$ [ilaç] grafiğe geçirilerek, kesim noktası/eğim oranından bağlanma sabiti $(K)$ bulunabilir. Buna göre, $2,09 \times 10^{3} \mathrm{~L} \mathrm{~mol}^{-1}$ olarak hesaplandı. Bu bağlanma sabiti değerinin klasik bir interkalatör olarak bilinen etidiyum bromürün bağlanma sabiti değerinden $\left(K=1,23 \times 10^{5} \mathrm{~L} \mathrm{~mol}^{-1}\right)$ ve DPV yöntemi ile hesaplanan değerden daha düşük olduğu görüldü. dsDNA'nın immobilize edilmediği şartlar altında, 2-TU'nun dsDNA'ya nispeten daha 1lımlı bağlandığı şeklinde açıklanabilir [31].

\section{SONUÇLAR}

$\mathrm{Bu}$ çalışmada, poli(bromokrezol moru) ile modifiye edilmiş camsı karbon elektroda dsDNA elektrokimyasal yolla immobilize edilerek, 2-tiyourasil (2-TU) tayini için ilk kez bir DNA biyosensörü hazırlandı. 2-TU ve dsDNA molekülünün etkileştirilmesi sonrası, guanin sinyalindeki azalma, 2-TU'nun tayini için kullanıldı. 2-TU için doğrusal çalışma aralığı $0,1-50 \mathrm{mg} \mathrm{L}^{-1}$ ve gözlenebilme sınırı $0,033 \mathrm{mg} \mathrm{L}^{-1}$ olarak belirlendi. Bunun yanında söz konusu DNA biyosensörü kullanılarak, 2-TU ve dsDNA arasındaki etkileşimin tipi aydınlatılmaya çalışıldı ve başlıca bağlanma modunun interkalasyon olduğu belirlendi. Benzer şekilde, etkileşim tipi spektroskopik olarak da çalışıldı. Çözeltideki 2-TU derişimi arttıkça, yaklaşık $260 \mathrm{~nm}$ dalga boyunda gözlenen dsDNA pik absorbansının arttığı ve daha uzun dalga boylarına doğru hafif bir kayma gösterdiği belirlendi. Ayrıca, $K$ bağlanma sabiti hem DPV hem de UV-Görünür bölge moleküler absorpsiyon spektroskopisi yöntemiyle hesaplandı. Hazırlanan biyosensör ile gerçek numuneye ilave edilen 2-TU'nin tayini başarıly gerçekleştirildi.

\section{TEŞEKKÜR}

Yazarlar 2015-41 nolu proje ile destek sağlayan Kütahya Dumlupınar Üniversitesi Bilimsel Araştırma Projeleri Birimine ve Burcu Demir'e yüksek lisans tez dönemi boyunca Yurtiçi Öncelikli Alanlar Yüksek Lisans Burs Programı (2210-C) kapsamında burs sağlayan Türkiye Bilimsel ve Teknolojik Araştırma Kurumuna (TÜBİTAK) teşekkür ederler. 


\section{KAYNAKLAR}

[1] Pattar, V. P., \& Nandibewoor, S. T. (2016). Staircase voltammetric determination of 2-thiouracil in pharmaceuticals and human biological fluids at polyaniline and polypyrrole film modified sensors. Sensors and Actuators A: Physical, 250, 40-47.

[2] Shah, A., Nosheen, E., Zafar, F., uddin, S. N., Dionysiou, D. D., Badshah, A., . . Khan, G. S. (2012). Photochemistry and electrochemistry of anticancer uracils. Journal of Photochemistry and Photobiology B: Biology, 117, 269-277.

[3] Palumbo, A., d'Ischia, M., \& Cioffi, F. A. (2000). 2-Thiouracil is a selective inhibitor of neuronal nitric oxide synthase antagonising tetrahydrobiopterin-dependent enzyme activation and dimerisation. FEBS Letters, 485(2), 109-112.

[4] Sułkowska, A., Równicka, J., Bojko, B., \& Sułkowski, W. (2003). Interaction of anticancer drugs with human and bovine serum albumin. Journal of Molecular Structure, 651-653, 133-140.

[5] Saleh, T. A., Al-Shalalfeh, M. M., \& Al-Saadi, A. A. (2018). Silver loaded graphene as a substrate for sensing 2-thiouracil using surface-enhanced Raman scattering. Sensors and Actuators B: Chemical, 254, 1110-1117.

[6] Beheshti, A., Riahi, S., Pourbasheer, E., Ganjali, M. R., \& Norouzi, P. (2010). Simultaneous Spectrophotometric Determination of 2-Thiouracil and 2-Mercaptobenzimidazole in Animal Tissue Using Multivariate Calibration Methods: Concerns and Rapid Methods for Detection. Journal of Food Science, 75(2), C135-C139.

[7] Chi, Y., Duan, J., Lin, S., \& Chen, G. (2006). Flow Injection Analysis System Equipped with a Newly Designed Electrochemiluminescent Detector and Its Application for Detection of 2-Thiouracil. Analytical Chemistry, 78(5), 1568-1573.

[8] Shahrokhian, S., Hamzehloei, A., Thaghani, A., \& Mousavi, S. R. (2004). Electrocatalytic Oxidation of 2Thiouracil and 2-Thiobarbituric Acid at a Carbon-Paste Electrode Modified with Cobalt Phthalocyanine. Electroanalysis, 16(11), 915-921.

[9] Gokavi, N. M., Patil, S. M., \& Nandibewoor, S. T. (2015). Fabrication of Polyethylene Glycol Modified Carbon Paste Electrode for the Sensitive Determination of Anti-thyroidal Drug 2-Thio-Uracil in Human Biological Fluids. Analytical Chemistry Letters, 5(4), 239-250.

[10] Bukkitgar, S. D., Shetti, N. P., \& Kulkarni, R. M. (2017). Electro-oxidation and determination of 2thiouracil at $\mathrm{TiO} 2$ nanoparticles-modified gold electrode. Surfaces and Interfaces, 6, 127-133.

[11] Liu, Y., Zou, Q.-H., Xie, M.-X., \& Han, J. (2007). A novel approach for simultaneous determination of 2mercaptobenzimidazole and derivatives of 2-thiouracil in animal tissue by gas chromatography/mass spectrometry. Rapid Communications in Mass Spectrometry, 21(9), 1504-1510.

[12] Kurbanoglu, S., Dogan-Topal, B., Rodriguez, E. P., Bozal-Palabiyik, B., Ozkan, S. A., \& Uslu, B. (2016). Advances in electrochemical DNA biosensors and their interaction mechanism with pharmaceuticals. Journal of Electroanalytical Chemistry, 775, 8-26.

[13] Florea, A., Guo, Z., Cristea, C., Bessueille, F., Vocanson, F., Goutaland, F., . . J Jaffrezic-Renault, N. (2015). Anticancer drug detection using a highly sensitive molecularly imprinted electrochemical sensor based on an electropolymerized microporous metal organic framework. Talanta, 138, 71-76. 
[14] Sirajuddin, M., Ali, S., \& Badshah, A. (2013). Drug-DNA interactions and their study by UV-Visible, fluorescence spectroscopies and cyclic voltametry. Journal of Photochemistry and Photobiology B: Biology, 124, 1-19.

[15] Rauf, S., Gooding, J. J., Akhtar, K., Ghauri, M. A., Rahman, M., Anwar, M. A., \& Khalid, A. M. (2005). Electrochemical approach of anticancer drugs-DNA interaction. Journal of Pharmaceutical and Biomedical Analysis, 37(2), 205-217.

[16] Dogan-Topal, B., Bozal-Palabiyik, B., Ozkan, S. A., \& Uslu, B. (2014). Investigation of anticancer drug lapatinib and its interaction with dsDNA by electrochemical and spectroscopic techniques. Sensors and Actuators B: Chemical, 194, 185-194.

[17] Oliveira-Brett, A. M. (2008). Electrochemical DNA Assays. In P. N. Bartlett (Ed.), Bioelectrochemistry: Fundamentals Experimental Techniques and Applications (pp. 411-442).

[18] Kurbanoglu, S., Dogan-Topal, B., Hlavata, L., Labuda, J., Ozkan, S. A., \& Uslu, B. (2015). Electrochemical investigation of an interaction of the antidepressant drug aripiprazole with original and damaged calf thymus dsDNA. Electrochimica Acta, 169, 233-240.

[19] Koyuncu Zeybek, D., Demir, B., Zeybek, B., \& Pekyardımcı, Ş. (2015). A sensitive electrochemical DNA biosensor for antineoplastic drug 5-fluorouracil based on glassy carbon electrode modified with poly(bromocresol purple). Talanta, 144, 793-800.

[20] Ersin, D., Onur, I., Recai, I., \& Hassan, Y. A.-E. (2018). Voltammetric Determination of Ophthalmic Drug Dexamethasone Using Poly-glycine Multi Walled Carbon Nanotubes Modified Paste Electrode. Current Analytical Chemistry, 14(1), 83-89.

[21] Yang, G., Yan, J., Qi, F., \& Sun, C. (2010). High Sensitivity and Reproducibility of a Bismuth/Poly(bromocresol purple) Film Modified Glassy Carbon Electrode for Determination of Trace Amount of Cadmium by Differential Pulse Anodic Stripping Voltammetry. Electroanalysis, 22(22), 27292738.

[22] Carter, M. T., Rodriguez, M., \& Bard, A. J. (1989). Voltammetric studies of the interaction of metal chelates with DNA. 2. Tris-chelated complexes of cobalt(III) and iron(II) with 1,10-phenanthroline and 2,2'-bipyridine. Journal of the American Chemical Society, 111(24), 8901-8911.

[23] Gokavi, N. M., Pattar, V. P., Bagoji, A. M., \& Nandibewoor, S. T. (2013). Square Wave Voltammetric Determination of 2-Thiouracil in Pharmaceuticals and Real Samples Using Glassy Carbon Electrode. International Journal of Electrochemistry, 2013, 8.

[24] Bagoji, A. M., Gokavi, N. M., Pattar, V. P., \& Nandibewoor, S. T. (2015). Fabrication, characterization and application of NiSO4 modified carbon paste electrode for the detection of 2-thiouracil in biological fluids. Analytical and Bioanalytical Electrochemistry, 7(6), 684-700.

[25] Pattar, V. P., \& Nandibewoor, S. T. (2015). Polybenzoin Based Sensor for Determination of 2thiouracil in Biological Fluids and Pharmaceutical Formulations. Journal of the Chinese Chemical Society, 62(3), 287295.

[26] Pattar, V. P., Bagoji, A. M., Gokavi, N. M., \& Nandibewoor, S. T. (2014). Electrochemical determination of 2-thiouracil in pharmaceuticals and real samples using gold electrode. Analytical and Bioanalytical Electrochemistry, 6(1), 1-15.

[27] Nawaz, H., Rauf, S., Akhtar, K., \& Khalid, A. M. (2006). Electrochemical DNA biosensor for the study of ciprofloxacin-DNA interaction. Analytical Biochemistry, 354(1), 28-34. 
[28] Chu, X., Shen, G.-L., Jiang, J.-H., Kang, T.-F., Xiong, B., \& Yu, R.-Q. (1998). Voltammetric studies of the interaction of daunomycin anticancer drug with DNA and analytical applications. Analytica Chimica Acta, 373(1), 29-38.

[29] Ibrahim, M. S. (2001). Voltammetric studies of the interaction of nogalamycin antitumor drug with DNA. Analytica Chimica Acta, 443(1), 63-72.

[30] Rahban, M., Divsalar, A., Saboury, A. A., \& Golestani, A. (2010). Nanotoxicity and Spectroscopy Studies of Silver Nanoparticle: Calf Thymus DNA and K562 as Targets. The Journal of Physical Chemistry C, 114(13), 5798-5803.

[31] Dimitrakopoulou, A., Dendrinou-Samara, C., Pantazaki, A. A., Alexiou, M., Nordlander, E., \& Kessissoglou, D. P. (2008). Synthesis, structure and interactions with DNA of novel tetranuclear, [Mn4(II/II/II/IV)] mixed valence complexes. Journal of Inorganic Biochemistry, 102(4), 618-628. 